\title{
An All-Inclusive Proof of Beal's Conjecture
}

\author{
Stephen M. Marshall
}

Senior Engineer and Mathematician

\section{Abstract}

This paper presents a complete and exhaustive proof of the Beal Conjecture. The approach to this proof uses the Fundamental Theorem of Arithmetic as the basis for the proof of the Beal Conjecture. The Fundamental Theorem of Arithmetic states that every number greater than 1 is either prime itself or is unique product of prime numbers. The prime factorization of every number greater than 1 is used throughout every section of the proof of the Beal Conjecture Fundamental Theorem of Arithmetic, this approach to proving the Beal Conject re would be possible.

\section{Introduction}

In 1997 an amateur mathematician and Texas banker named And discove de Beal Conjecture. The Beal Conjecture states that the only solutions to equation $x+B^{y}=C^{z}$, when $\mathrm{A}, \mathrm{B}, \mathrm{C}$, are positive integers, and $\mathrm{x}, \mathrm{y}$, and $\mathrm{z}$ are positive teg greater $\mathrm{t}$, 2 , are those in which $\mathrm{A}, \mathrm{B}$, and $\mathrm{C}$ have a common prime factor. The truth Last Theorem, which states that there are no solutions th the equation $a b^{n}=c^{n}$ where $a, b$, and $\mathrm{c}$ are positive integers and $\mathrm{n}$ is a positive integer greate than 2. More than three hundred years ago, Pierre de Fermat claimed he had a proof but did not 1 ve a record of it. The theorem was finally proved in the 1990s by Andrew Wiles, together with Ri Tayl r. Both the Beal Conjecture and Fermat's Last Theorem are typical of man atements number theory: easy to say, but extremely difficult to prove.

\section{The Proof}

The Beal Conjecture states the

If $\mathrm{A}^{\mathrm{x}}+\mathrm{B}^{\mathrm{y}}=\mathrm{C}^{\mathrm{z}}$, where $\mathrm{A}, \mathrm{B}, \mathrm{C}, \mathrm{x}, \mathrm{y} \quad \mathrm{z}$ are positive integers and $\mathrm{x}, \mathrm{y}$ and $\mathrm{z}$ are all greater than 2, then $\mathrm{A}, \mathrm{B}$ and $\mathrm{C}$ must $\mathrm{h}$ common factor.

We will prove for ever pos integer, or A, B, and C and for every $\mathrm{x}, \mathrm{y}$ and $\mathrm{z}$ that are greater than

2 that the Beal $C$ nject re is true. nis proof is based on the Fundamental Theorem of Arithmetic; therefore we be in the proof of Beal's Conjecture with a proof (WIKIPEDIA ${ }^{\star}$ ) of the Fundamental 1 rem of rithmetic below:

\section{Proof o Fun imenta ceorem of Arithmetic}

In Nun $T$ fundamental theorem of arithmetic, also called the unique factorization theorem the unique-prime-factorization theorem, states that every number greater than 1 is either prim self or is the product of prime numbers, and that, although the order of the primes in the second case is arbitrary, the primes themselves are not. For example,

$$
1200=2^{4} \times 3^{1} \times 5^{2}=3 \times 2 \times 2 \times 2 \times 2 \times 5 \times 5=5 \times 2 \times 3 \times 2 \times 5 \times 2 \times 2=. . \text { etc. }
$$

The theorem is stating two things: first, that 1200 can be represented as a product of primes, and second, no matter how this is done, there will always be four $2 \mathrm{~s}$, one 3 , two $5 \mathrm{~s}$, and no other primes in the product.

The requirement that the factors be prime is necessary: factorizations containing composite numbers may not be unique (e.g. $12=2 \times 6=3 \times 4$ ).

The proof uses Euclid's lemma Elements VII, 30): if a prime $p$ divides the product of two natural numbers $a$ and $b$, then $p$ divides $a$ or $p$ divides $b$ (or both). 


\section{Existence}

By induction: assume it is true for all numbers less than $n$. If $n$ is prime, there is nothing more to prove. Otherwise, there are integers $a$ and $b$, where $n=a b$ and $1<a \leq b<n$. By the induction hypothesis, $a=p_{1} p_{2} \ldots p_{n}$ and $b=q_{1} q_{2} \ldots q_{m}$ are products of primes. But then $n=a b=$ $p_{1} p_{2} \ldots p_{n} q_{1} q_{2} \ldots q_{m}$ is the product of primes. In the base case, 2 is a trivial product of primes.

\section{Uniqueness}

Assume that $s>1$ is the product of prime numbers in two different ways:

$$
\begin{aligned}
\mathrm{s} & =\mathrm{p}_{1} \mathrm{p}_{2} \ldots \mathrm{p}_{\mathrm{m}} \\
& =\mathrm{q}_{1} \mathrm{q}_{2} \ldots \mathrm{q}_{\mathrm{n}}
\end{aligned}
$$

We must show $m=n$ and that the $q_{j}$ are a rearrangement of the $p_{i}$.

By Euclid's lemma $p_{1}$ must divide one of the $q_{j}$; relabeling the $q_{j}$ if necessa say $p 1$ di ides $q_{1}$. But $q 1$ is prime, so its only divisors are itself and 1 . Therefore, $p_{1}=q_{1}, 0$ that

$$
\begin{aligned}
& \frac{s}{p_{1}}=\mathrm{p}_{2} \ldots \mathrm{p}_{\mathrm{m}} \\
& =\mathrm{q}_{2} \ldots \mathrm{qn}
\end{aligned}
$$
Reasoning the same way, $p_{2}$ must equal one of the rem artmos $q j$. Rely again if necessary,
say $p_{2}=q_{2}$. Then

This can be done for all $m$ of the $p_{i}$, showing th $m \leq n$. If there were any $q_{j}$ left over we would have

which is imposs ofe, si ce the pro uct of numbers greater than 1 cannot equal 1 . Therefore $m=$ $n$ and every $q j$ is $i$.

The me ol theorem of arithmetic can also be proved without using Euclid's lemma, as follows: Assume $s>$ is the smallest positive integer which is the product of prime numbers in two differen ays. If $s$ were prime then it would factor uniquely as itself, so there must be at least two prin,es in each factorization of $s$ :

$$
\begin{aligned}
\mathrm{s} & =\mathrm{p}_{1} \mathrm{p}_{2} \ldots \mathrm{p}_{\mathrm{m}} \\
& =\mathrm{q}_{1} \mathrm{q}_{2} \ldots \mathrm{q}_{\mathrm{n}}
\end{aligned}
$$

If any $p_{i}=q_{j}$ then, by cancellation, $s / p_{i}=s / q_{j}$ would be a positive integer greater than 1 with two distinct factorizations. But $s / p_{i}$ is smaller than $s$, meaning $s$ would not actually be the smallest such integer. Therefore every $p_{i}$ must be distinct from every $q_{j}$. 
Without loss of generality, take $p_{1}<q_{1}$ (if this is not already the case, switch the $p$ and $q$ designations.) Consider

$$
\mathrm{t}=\left(\mathrm{q}_{1}-\mathrm{p}_{1}\right)\left(\mathrm{q}_{2} \ldots \mathrm{q}_{\mathrm{n}}\right)
$$

and note that $1<q_{2} \leq t<s$. Therefore $t$ must have a unique prime factorization. By rearrangement we see,

$$
\begin{gathered}
\mathrm{t}=\mathrm{q}_{1}\left(\mathrm{q}_{2}-\mathrm{p}_{\mathrm{n}}\right)-\mathrm{p}_{1}\left(\mathrm{q}_{2} \ldots \mathrm{q}_{\mathrm{n}}\right) \\
=\mathrm{s}-\mathrm{p}_{1}\left(\mathrm{q}_{2} \ldots \mathrm{q}_{\mathrm{n}}\right) \\
=\mathrm{p}_{1}\left(\left(\mathrm{p}_{2} \ldots \mathrm{p}_{\mathrm{m}}\right)-\left(\mathrm{q}_{2} \ldots \mathrm{q}_{\mathrm{n}}\right)\right)
\end{gathered}
$$

Here $u=\left(\left(p_{2} \ldots p_{m}\right)-\left(q_{2} \ldots q_{n}\right)\right)$ is positive, for if it were negative or zero th so wa be its product with $p_{1}$, but that product equals $t$ which is positive. So $u$ is either or factor nto primes. In either case, $t=p_{1} u$ yields a prime factorization of $t$, which we kn to b nique, $0 p_{1}$ appears in the prime factorization of $t$.

If $\left(q_{1}-p_{1}\right)$ equaled 1 then the prime factorization of $t$ would be all from appearing. Thus $\left(q_{1}-p_{1}\right)$ is not 1 , but is positive, so it factor $r_{h}$ ). This yields a prime factorization of

which we know is unique. Now, $p_{1}$ appears in the pr fe factorization of $t$, and it is not equal to any $q$, so it must be one of the $r$ 's. That means $p_{1}$ is a ctor of $\left(q_{1}-p_{1}\right)$, so there exists a positive integer $k$ such that $p_{1} k=\left(q_{1}-p_{1}\right)$, and therefore

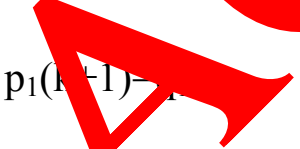

But that means $q_{1}$ has a proper fow tion, $s$ it is not a prime number. This contradiction showsthat $s$ does not actually $b$ two differen prime factorizations. As a result, there is no smallest positive integer witb nu actorizations, hence all positive integers greater than 1 factor uniquely into imes.

\section{Proof of Beal's Conichre}

First we shall ar me th the BealConjecture is false, specifically:

If $\mathrm{A}^{\mathrm{x}}+\mathrm{B}^{\mathrm{y}}=\mathrm{C}^{\mathrm{z}}$, e $\mathrm{A}, \mathrm{B}, \mathrm{X}, \mathrm{x}, \mathrm{y}$ and $\mathrm{z}$ are positive integers and $\mathrm{x}, \mathrm{y}$ and $\mathrm{z}$ are all greater than 2 , then $\mathrm{A} d \mathrm{C} \mathrm{Ca}_{\mathrm{a}} \mathrm{t}$ h $\mathrm{Ne}$ a common prime factor.

$$
\mathrm{A}^{\mathrm{x}}+\mathrm{B}^{\mathrm{y}}=\mathrm{C}^{\mathrm{z}}
$$

Factoring the 1 side, $\mathrm{A}^{\mathrm{x}}\left(1+\mathrm{B}^{\mathrm{y}} / \mathrm{A}^{\mathrm{x}}\right)=\mathrm{C}^{\mathrm{z}}$

Since $A, B$, and $C$ are all positive integers then $A^{x}, B^{y}$, and $C^{z}$ then for $C^{z}$ to be a positive integer $\left(1+\mathrm{B}^{\mathrm{y}} / \mathrm{A}^{\mathrm{x}}\right)$ must be a positive integer (first possibility) or a fraction that has a factor of $\mathrm{A}^{\mathrm{x}}$ in its denominator so by reducing $\mathrm{A}^{\mathrm{x}}\left(1+\mathrm{B}^{\mathrm{y}} / \mathrm{A}^{\mathrm{x}}\right)$ it is equal to the integer $\mathrm{C}^{\mathrm{z}}$ (second possibility).

\section{Proof of first Possibility}

For the first case if $\left(1+\mathrm{B}^{\mathrm{y}} / \mathrm{A}^{\mathrm{x}}\right)=$ positive integer

Then, $\mathrm{B}^{\mathrm{y}} / \mathrm{A}^{\mathrm{x}}$ must be an integer, which implies that $\mathrm{B}^{\mathrm{y}}$ and $\mathrm{A}^{\mathrm{x}}$ have a common prime factors in accordance with (IAW) the Fundamental Theorem of Arithmetic. Furthermore, $\mathrm{B}^{\mathrm{y}}$ must be 
divisible by $\mathrm{A}^{\mathrm{x}}$ since $\mathrm{B}^{\mathrm{y}} / \mathrm{A}^{\mathrm{x}}$ is an integer, then $\mathrm{A}^{\mathrm{x}}$ must be reduced to 1 for $\mathrm{B}^{\mathrm{y}} / \mathrm{A}^{\mathrm{x}}$ to be reduced to a positive integer.

\section{Proof that $B^{y} / A^{x}$ do not have any common prime factors using our assumption that Beal's Conjecture is false}

Factoring $\mathrm{B}^{\mathrm{y}} / \mathrm{A}^{\mathrm{x}}$, then

$$
\mathrm{B}^{\mathrm{y}} / \mathrm{A}^{\mathrm{x}}=\left(\mathrm{B}_{1}\right)\left(\mathrm{B}_{2}\right)\left(\mathrm{B}_{3}\right) \ldots \ldots(\mathrm{By}-2)(\mathrm{By}-1)(\mathrm{By})
$$

$$
\left(A_{1}\right)\left(A_{2}\right)\left(A_{3}\right) \ldots \ldots(A x-2)(A x-1)(A x)
$$

Since $B=B_{1}=B_{2}=B y-1=B y$ and $A=A_{1}=A_{2}=A x-1=A x$, then none of the eries or is or A's have common prime factors since in our assumption we assumed that Beg Conjectur vas false and $\mathrm{A}, \mathrm{B}$ and $\mathrm{C}$ cannot have a common prime factor. Therefore, $\mathrm{B}^{\mathrm{y}}$ ar $\mathrm{A}^{\mathrm{x}} \mathrm{a}$ t hav any common prime factors.

However, IAW the Fundamental Theorem of Arithmetic every int $>1$ Amas be a unique series of prime factors, therefore $\mathrm{B}^{\mathrm{y}} / \mathrm{A}^{\mathrm{x}}$ can only be an integer if nd have co rmon prime factors. Therefore since $\mathrm{B}^{\mathrm{y}} / \mathrm{A}^{\mathrm{x}}$ cannot be an integer accordin our ass on that Beal's Conjecture is false and $\mathrm{A}, \mathrm{B}$ and $\mathrm{C}$ cannot have a common rime tor. However $\mathrm{B}^{\mathrm{y}} / \mathrm{A}^{\mathrm{x}}$ must be an integer, therefore $\mathrm{B}^{\mathrm{y}}$ and $\mathrm{A}^{\mathrm{x}}$ must have common $\mathrm{p}$ factors assumption that $\mathrm{A}$, $\mathrm{B}$, and $\mathrm{C}$ cannot have a common prime factor is false nd Beal's Conjec ure must be true for this first possibility.

\section{Proof of second Possibility}

The only other possibility is for $\left(1+\mathrm{B}^{\mathrm{y}} / \mathrm{A}^{\mathrm{x}}\right)$ to $\mathrm{action}$ that has a factor of $\mathrm{A}^{\mathrm{x}}$ in its denominator so by reducing $A^{x}\left(1+B^{y} / A^{x}\right)$ it is eq 1 to the integer $C^{z}$.

Let $\mathrm{A}_{\mathrm{F}}^{\mathrm{x}}=\mathrm{a}$ factor of $\mathrm{A}^{\mathrm{x}}$

Therefore, $\left(1+\mathrm{B}^{\mathrm{y}} / \mathrm{A}^{\mathrm{x}}\right)=\mathrm{N} / \mathrm{A}^{\mathrm{x}}$

Reducing, $\mathrm{A}_{\mathrm{F}}^{\mathrm{x}}+\left(\mathrm{B}^{\mathrm{y}} \mathrm{A}_{\mathrm{F}}^{\mathrm{x}}\right) / \mathrm{A}^{\mathrm{x}}<\mathrm{N}^{-}$

$A^{x}$ is a positive integer 10 is a factor $/ A^{x}$ which is a positive integer.

Therefore, $\left(\mathrm{B}^{\mathrm{y}} \mathrm{A}_{\mathrm{F}}^{\mathrm{x}}\right) / \mathrm{A}^{\mathrm{x}}$, nt be , nteger, then rearranging, $\left(\mathrm{B}^{\mathrm{y}} \mathrm{A}_{\mathrm{F}}^{\mathrm{x}}\right) / \mathrm{A}^{\mathrm{x}}=\left(\mathrm{B}^{\mathrm{y}}\right) /\left(\mathrm{A}^{\mathrm{x}} / \mathrm{A}^{\mathrm{x}} \mathrm{F}\right)$

Let $A^{X-R}=$ the paltiplication of $^{X}$ es of prime factors remaining for $A^{x}$ after reducing $A^{x} / A^{x}$ to an integer.

Let $\mathrm{A}^{\mathrm{x}} \overline{\overline{\mathrm{r}}}$ the mul cation $\mathrm{c}$ series of prime factors remaining for $\mathrm{A}_{\mathrm{F}}^{\mathrm{x}}$ after reducing $\mathrm{A}^{\mathrm{x}} / \mathrm{A}^{\mathrm{x}}{ }_{\mathrm{F}}$ to an integer.

$\mathrm{A}_{\mathrm{r}}^{\mathrm{x}} \mathrm{Ca}_{\mathrm{a}}$ prime factor with $\mathrm{B}^{\mathrm{y}}$ since the prime factors for $\mathrm{A}_{\mathrm{r}} \mathrm{A}^{\mathrm{x}}$ is a subset of the prime factors for and according to our assumption and earlier proof that $\mathrm{B}^{\mathrm{y}}$ and $\mathrm{A}^{\mathrm{x}}$ do not have any common prim factors, then $\mathrm{A}^{\mathrm{x}}{ }_{r}$ cannot have any common prime factors with $\mathrm{B}^{\mathrm{y}}$. Using the same logic, $\mathrm{A}^{\mathrm{X}-\mathrm{R}}$ cannot have a prime factor with $\mathrm{B}^{\mathrm{y}}$ since the prime factors for $\mathrm{A}^{\mathrm{X}-\mathrm{R}}$ is a subset of the prime factors for $\mathrm{A}^{\mathrm{x}}$ and according to our assumption and earlier proof that $\mathrm{B}^{\mathrm{y}}$ and $\mathrm{A}^{\mathrm{x}}$ do not have any common prime factors, then $\mathrm{A}^{\mathrm{X}-\mathrm{R}} \mathrm{A}^{\mathrm{x}}{ }_{\mathrm{r}}$ cannot have any common prime factors with $\mathrm{B}^{\mathrm{y}}$.

More specifically,

$$
\left(\mathrm{B}^{\mathrm{y}}\right) /\left(\mathrm{A}^{\mathrm{X}-\mathrm{R}}\right)\left(\mathrm{A}_{\mathrm{r}}^{\mathrm{x}}\right)=\left(\mathrm{B}_{1}\right)\left(\mathrm{B}_{2}\right)\left(\mathrm{B}_{3}\right) \ldots \ldots(\mathrm{By}-\underline{2})(\mathrm{By}-\underline{1})\left(\mathrm{B}_{\mathrm{y}}\right)
$$

$$
\left(A_{1}\right)\left(A_{2}\right)\left(A_{3}\right) \ldots \ldots(A x-R-1)(A x-R)\left(A_{r}^{x}\right)
$$


None of the A's 1 through X-R have a common prime factor with any of the B's 1 through $\mathrm{Y}$ since $\mathrm{B}=\mathrm{B}_{1}=\mathrm{B}_{2}=\mathrm{B}_{\mathrm{y}}$ and $\mathrm{A}=\mathrm{A}_{1}=\mathrm{A}_{2}=\mathrm{Ax}-\mathrm{R}$ and according to our assumption $\mathrm{A}, \mathrm{B}$, and $\mathrm{C}$ do not have any common prime factors. Since $\mathrm{A}^{\mathrm{x}}{ }_{\mathrm{r}}$ is a factor of $\mathrm{A}^{\mathrm{x}}$ which has no common factors with $\mathrm{B}^{\mathrm{y}}$ according to our first proof. Therefore, $\mathrm{A}^{\mathrm{x}}{ }_{\mathrm{r}}$ has no common prime factors with $\mathrm{B}^{\mathrm{y}}$, finally $\mathrm{B}^{\mathrm{y}}$ and $\left(\mathrm{A}^{\mathrm{X}-\mathrm{R}}\right)\left(\mathrm{A}_{\mathrm{r}}^{\mathrm{X}}\right)$ have no common prime factors.

However, for our second and final possibility, we have shown earlier that $\left(\mathrm{B}^{\mathrm{y}}\right) /\left(\mathrm{A}^{\mathrm{x}} / \mathrm{A}^{\mathrm{x}}{ }_{\mathrm{F}}\right)$ must be integer. Since $\left(B^{y}\right) /\left(A^{x} / A_{F}^{x}\right)=\left(B^{y} A_{F}^{x}\right) / A^{x}=\left(B^{y}\right) /\left(A^{X-R}\right)\left(A^{x}\right)=$ integer. Therefore, since:

$$
\left(\mathrm{B}^{\mathrm{y}}\right) /\left(\mathrm{A}^{\mathrm{X}-\mathrm{R}}\right)\left(\mathrm{A}_{\mathrm{r}}^{\mathrm{x}}\right)=\left(\mathrm{B}_{1}\right)\left(\mathrm{B}_{2}\right)\left(\mathrm{B}_{3}\right) \ldots \ldots \ldots(\mathrm{By}-\underline{2})(\mathrm{By}-1)\left(\mathrm{B}_{\mathrm{y}}\right)
$$

$\left(A_{1}\right)\left(A_{2}\right)\left(A_{3}\right) \ldots \ldots(A x-R-1)(A x-R)\left(A_{r}^{x}\right.$

Therefore, since $\mathrm{B}=\mathrm{B}_{1}=\mathrm{B}_{2}=\mathrm{B}_{\mathrm{y}}$ and $\mathrm{A}=\mathrm{A}_{1}=\mathrm{A}_{2}=\mathrm{Ax}-\mathrm{R}$ then $\mathrm{A}$ and $\mathrm{B}$ mus ave con hon prime factors for $\left(\mathrm{B}^{\mathrm{y}}\right) /\left(\mathrm{A}^{\mathrm{X}-{ }^{\mathrm{R}}}\right)\left(\mathrm{A}^{\mathrm{x}}{ }_{\mathrm{r}}\right)$ to be an integer. Furthermore, $\mathrm{AW}$ the $\mathrm{C}$ ar ental Theorem of Arithmetic every integer $>1$ must be a unique series prim actars, nerefore $\left(\mathrm{B}^{\mathrm{y}}\right) /\left(\mathrm{A}^{\mathrm{X}-\mathrm{R}^{\mathrm{R}}}\right)\left(\mathrm{A}_{\mathrm{r}}^{\mathrm{x}}\right)$ is a unique series of prime factors that can only/gn ger if $A$ and $\mathrm{B}$ have common prime factors.

Now we shall address the case when either $\mathrm{A}, \mathrm{B}$, or $\mathrm{C}$ are ed al $\mathrm{h}$ For $\mathrm{A}^{\mathrm{\lambda}}-\mathrm{B}^{\mathrm{y}}=\mathrm{C}^{\mathrm{z}}$ let $\mathrm{A}=$ 1 , then $1+B^{y}=C^{\mathrm{z}}$, then $1=C^{\mathrm{z}}-\mathrm{B}^{\mathrm{y}}$, since $\mathrm{Y}$ and $\mathrm{Z}$ are $\mathrm{Mn}>2$, since $\mathrm{B}$ and $\mathrm{C}>1$ it is only possible for $\mathrm{C}^{\mathrm{z}}-\mathrm{B}^{\mathrm{y}}$ to be greater than 1 , or equ to 0 only if $\mathrm{C}-\mathrm{B}^{\mathrm{y}}$. For example, the smallest number possible for either $\mathrm{B}$ or $\mathrm{C}$ is 2 . Since and $\mathrm{Z}$ are $\mathrm{b} \rightarrow \mathrm{th}>2$, then the lowest integer for $\mathrm{Y}$ or $\mathrm{Z}$ is 3. Then if lowest integer for $\mathrm{C}$ or $\mathrm{B}$ is 2 , n say $\mathrm{B}=2$, then $\mathrm{B}^{3}=2^{3}=8$, which is $>$ 1. If $\mathrm{C}^{\mathrm{z}} \neq \mathrm{B}^{\mathrm{y}}$ then the lowest integer $\mathrm{C}$ can bo is 3 , then $\quad 2^{3}=27$, and $\mathrm{C}^{\mathrm{z}}-\mathrm{B}^{\mathrm{y}}=27-8=19$ $>1$, so there is no solution for $\mathrm{A}^{\mathrm{x}}+\mathrm{B}^{\mathrm{y}}=\mathrm{C}^{\mathrm{z}}$ wh

Following the same logic we can show that if $\mathrm{B}=1$, Aen there is no solution for $\mathrm{A}^{\mathrm{x}}+\mathrm{B}^{\mathrm{y}}=\mathrm{C}^{\mathrm{z}}$. For $A^{x}+B^{y}=C^{z}$ let $B=1$, then $A^{x}=C^{z}$, $t$, n $1=C^{z}-A^{x}$, since $X$ and $Z$ are both $>2$, then since $\mathrm{A}$ and $\mathrm{C}>1$ it is only possib for $-\mathrm{A}^{\mathrm{x}}$ to $\mathrm{C}$ greater than 1 , or equal to 0 only if $\mathrm{C}^{\mathrm{z}}=\mathrm{A}^{\mathrm{x}}$. For example, the smallest num er si $\mathrm{A}$ or $\mathrm{C}$ is 2.Since $\mathrm{X}$ and $\mathrm{Z}$ are both $>2$, then the lowest integer for $\mathrm{X}$ or 7 is 3 . Th if lowest integer for $\mathrm{C}$ or $\mathrm{B}$ is 2 , then say $\mathrm{A}=2$, then $\mathrm{A}^{\mathrm{x}}=$ $2^{3}=8$, which is $>1$. If $\mathrm{C}^{\mathrm{x}}$ then the west integer $\mathrm{C}$ can be is 3 , then $\mathrm{C}^{3}=3^{3}=27$, and $\mathrm{C}^{\mathrm{z}}$ $\mathrm{A}^{\mathrm{x}}=27-8=19>1$, sere is solution for $\mathrm{A}^{\mathrm{x}}+\mathrm{B}^{\mathrm{y}}=\mathrm{C}^{\mathrm{z}}$ when $\mathrm{B}=1$.

Following similar ogic if $\mathrm{C}=1$, $/ \mathrm{A}^{\mathrm{x}}+\mathrm{B}^{\mathrm{y}}=1$, but the lowest integers that $\mathrm{A}$ and $\mathrm{B}$ can be is $\mathrm{A}=\mathrm{B}=1$, but $\quad \mathrm{A}^{\mathrm{x}} \mathrm{y}=1$ can be reduced to $1+1=1$, since $2 \neq 1$, then we have shown that there is no solution $\quad A^{x}+y=C^{z}$ when $C=1$. This also shows that if $A=B=C=1$, then that there is $\mathrm{S}$ tion fo $\mathrm{x}-\mathrm{B}^{\mathrm{y}}=\mathrm{C}^{\mathrm{z}}$ when $\mathrm{A}=\mathrm{B}=\mathrm{C}=1$. Also if two of $\mathrm{A}, \mathrm{B}$, or $\mathrm{C}$ are equal to 1, the $\mathrm{A}-\mathrm{B}=1$. hen $\mathrm{A}^{\mathrm{x}}+\mathrm{B}^{\mathrm{y}}=\mathrm{C}^{\mathrm{z}}$ can be reduced to $1+1=\mathrm{C}^{\mathrm{Z}}$ and $\mathrm{Z}>2$, then the lowest integer $\triangle$ oc $=3$. Then $1+1=\mathrm{C}^{3}$ but if $\mathrm{C}=$ then $2=1$, but $2 \neq 1$. If $\mathrm{C}=2$ then $1+1=$ $2^{Z}$. Again, smallest integer for $Z$ is $Z-3$, then $1+1=2^{3}=8$. But $1+1=2 \neq 8$, and following the, ame logic for all $\mathrm{C}$ integers, $\mathrm{C}>2$ will not have solutions either. We have shown there is no solution for $\mathrm{A}^{\mathrm{x}}+\mathrm{B}^{\mathrm{y}}=\mathrm{C}^{\mathrm{z}}$ when $\mathrm{A}=\mathrm{B}=1$.

Following similar logic as above for $\mathrm{A}=\mathrm{B}=1$, if any two of $\mathrm{A}, \mathrm{B}$, or $\mathrm{C}$ are equal to 1 , then it can easily be shown that there is no solution for $A^{x}+B^{y}=C^{z}$ when any two combinations of $A, B$, or $\mathrm{C}$ are equal to 1 .

The only remaining proof to completely prove that Beal's Conjecture is true is to show that $\mathrm{C}$ has a common prime factor with $\mathrm{A}$ and $\mathrm{B}$. We have already proven that $\mathrm{A}$ and $\mathrm{B}$ have a common prime factor and have show that $\mathrm{B}^{\mathrm{y}}$ and $\mathrm{A}^{\mathrm{x}}$ have a common prime factor.

$$
\mathrm{A}^{\mathrm{x}}+\mathrm{B}^{\mathrm{y}}=\mathrm{C}^{\mathrm{z}}
$$


Let $\mathrm{p}$ be a common prime factor of $\mathrm{B}^{\mathrm{y}}$ and $\mathrm{A}^{\mathrm{x}}$

Then $\mathrm{p}\left(\mathrm{A}^{\mathrm{x}} / \mathrm{p}+\mathrm{B}^{\mathrm{y}} / \mathrm{p}\right)=\mathrm{C}^{\mathrm{z}}$

Reducing, $\left(\mathrm{A}^{\mathrm{x}} / \mathrm{p}+\mathrm{B}^{\mathrm{y}} / \mathrm{p}\right)=\mathrm{C}^{\mathrm{z}} / \mathrm{p}$

Since $p$ is a common prime factor of $\mathrm{B}^{\mathrm{y}}$ and $\mathrm{A}^{\mathrm{x}}$, then $\mathrm{A}^{\mathrm{x}} / \mathrm{p}$ and $\mathrm{B}^{\mathrm{y}} / \mathrm{p}$ can both be reduced to integers. Therefore, since $\mathrm{A}^{\mathrm{x}} / \mathrm{p}$ and $\mathrm{B}^{\mathrm{y}} / \mathrm{p}$ are both integers then $\mathrm{C}^{\mathrm{z}} / \mathrm{p}$ is an integer, which is only possible if $\mathrm{p}$ is a common prime factor of $\mathrm{C}^{\mathrm{z}}$. Therefore, we have thoroughly proven that $\mathrm{A}, \mathrm{B}$, and $\mathrm{C}$ have common prime factors.

\section{Conclusion}

Our assumption that $\mathrm{A}, \mathrm{B}$, and $\mathrm{C}$ cannot have a common prime factor is false Beal's Conjecture must be true for this second possibility. Beal's Conjecture has alrea y been ven for the first possibility, therefore Beal's Conjecture is proven true for all poss ties and 1 $\mathrm{A}, \mathrm{B}$, and $\mathrm{C}$ positive integers and all $\mathrm{x}, \mathrm{y}, \mathrm{z}>2$.

\section{References}

[1] A Classical Introduction to Modern Number Theory, Authors ann Treland and Michael Rosen

[2] An Introduction to the Theory of Numbers, Authors: G. H. H. Edward M. Wright, and Andrew Wiles

[3] Wikipedia, the free encyclopedia, the Fundamental heorem of Arithłetic

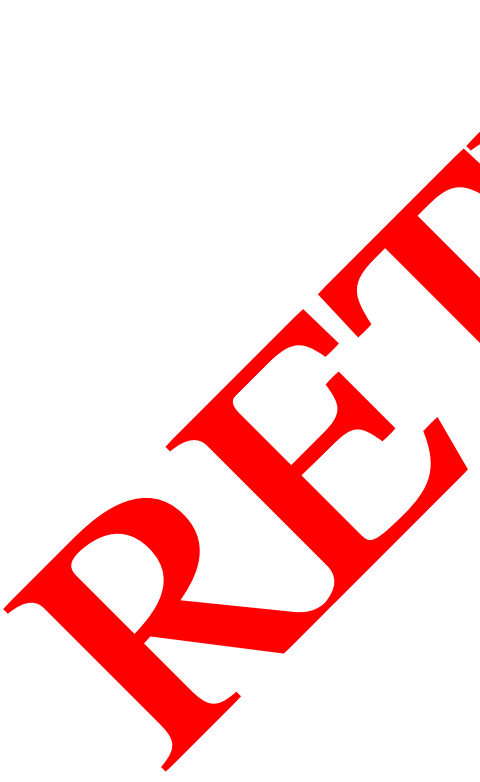

